Article

\title{
Hydrogen Uptake and Embrittlement of Carbon Steels in Various Environments
}

\author{
Anton Trautmann ${ }^{1}$, Gregor Mori ${ }^{1, *}$, Markus Oberndorfer ${ }^{2}$, Stephan Bauer ${ }^{2}$, \\ Christoph Holzer ${ }^{1}$ and Christoph Dittmann ${ }^{3}$ \\ 1 Department General, Analytical and Physical Chemistry, Montanuniversitaet Leoben, Franz-Josef-Strasse 18, \\ 8700 Leoben, Austria; anton.trautmann@unileoben.ac.at (A.T.); mori@unileoben.ac.at (C.H.) \\ 2 Green Gas Technology, RAG Austria AG, Schwarzenbergplatz 16, 1015 Vienna, Austria; \\ markus.oberndorfer@rag-austria.at (M.O.); stephan.bauer@rag-austria.at (S.B.) \\ 3 Research \& Development, voestalpine Tubulars GmbH \& Co KG, Alpinestrasse 17, 8652 Kindberg, Austria; \\ christoph.dittmann@vatubulars.com \\ * Correspondence: gregor.mori@unileoben.ac.at; Tel.: +43-3842-402-1250
}

Received: 6 July 2020; Accepted: 12 August 2020; Published: 14 August 2020

\begin{abstract}
To avoid failures due to hydrogen embrittlement, it is important to know the amount of hydrogen absorbed by certain steel grades under service conditions. When a critical hydrogen content is reached, the material properties begin to deteriorate. The hydrogen uptake and embrittlement of three different carbon steels (API 5CT L80 Type 1, P110 and 42CrMo4) was investigated in autoclave tests with hydrogen gas $\left(\mathrm{H}_{2}\right)$ at elevated pressure and in ambient pressure tests with hydrogen sulfide $\left(\mathrm{H}_{2} \mathrm{~S}\right) . \mathrm{H}_{2}$ gas with a pressure of up to 100 bar resulted in an overall low but still detectable hydrogen absorption, which did not cause any substantial hydrogen embrittlement in specimens under a constant load of $90 \%$ of the specified minimum yield strength (SMYS). The amount of hydrogen absorbed under conditions with $\mathrm{H}_{2} \mathrm{~S}$ was approximately one order of magnitude larger than under conditions with $\mathrm{H}_{2}$ gas. The high hydrogen content led to failures of the $42 \mathrm{CrMo} 4$ and P110 specimens.
\end{abstract}

Keywords: hydrogen embrittlement; hydrogen absorption; hydrogen gas; sour gas; autoclave tests

\section{Introduction}

When steels are exposed to hydrogen, their mechanical properties can deteriorate. This phenomenon is commonly referred to as hydrogen embrittlement and has been studied for 145 years [1]. Sir Harry Bhadeshia emphasized that one of the key elements in understanding and preventing hydrogen embrittlement is knowing the amount of hydrogen that a material absorbs under certain conditions [2]. In dry conditions, i.e., without electrochemical reactions such as corrosion, the only possible source for absorbable hydrogen atoms is the hydrogen gas $\left(\mathrm{H}_{2}\right)$. The hydrogen molecule dissociates to two adsorbed hydrogen atoms $\left(\mathrm{H}_{\mathrm{ad}}\right)$ on the steel surface. $\mathrm{H}_{\mathrm{ad}}$ can subsequently be absorbed by the material $\left(\mathrm{H}_{\mathrm{ab}}\right)$. The hydrogen solubility of metal $(\mathrm{S})$ is depicted in Sieverts' law [3]:

$$
\mathrm{S}=\mathrm{S}_{0} \cdot \sqrt{\mathrm{p}} \cdot \mathrm{e}^{-\frac{\Delta \mathrm{H}}{\mathrm{R} \cdot \mathrm{T}}}
$$

where $\mathrm{S}_{0}$ is the solubility constant, $\mathrm{p}$ is the partial pressure of the $\mathrm{H}_{2}$ gas, $\Delta \mathrm{H}$ the heat of solution, $\mathrm{R}$ the universal gas constant and $\mathrm{T}$ the absolute temperature. The equation expresses the pressure and temperature dependence of the hydrogen solubility as first described by Sieverts and Krumbhaar [4].

In conditions with electrolyte, corrosion of steel can be a second potential source for hydrogen. The electrons, that are released when the metal is dissolved, reduce the protons $\left(\mathrm{H}^{+}\right)$present in the 
electrolyte to hydrogen atoms. If some of the hydrogen atoms do not recombine to molecules, they can get adsorbed and further absorbed by the material. It is known in the oil and gas industry that hydrogen sulfide $\left(\mathrm{H}_{2} \mathrm{~S}\right)$ can cause many problems, such as sulfide stress cracking (SSC). $\mathrm{H}_{2} \mathrm{~S}$ hinders the recombination of hydrogen atoms and therefore promotes their absorption $[5,6]$.

The crucial role of the microstructure on hydrogen solubility and thus the possible hydrogen uptake of a material was shown by Siegl et al. [7] in permeation experiments. The difference in the solubility of pure iron between the recrystallized condition and the severely plastically deformed material was a factor of approximately 4000. Hydrogen traps and consequently the local hydrogen concentration strongly influence diffusion $[8,9]$.

To initiate a crack three things have to come together: a critical hydrogen concentration, a certain stress level and a susceptible material [10]. In addition to strength [11], microstructure strongly influences the susceptibility of a material to SSC and to hydrogen embrittlement [12]. Tempered martensite generally shows good resistance to SSC [13], but sensitivity increases with increasing strength [11,14]. The volume fraction of tempered martensite has to be as high as possible [15]. A minimum martensite fraction of $95 \%$ is standardized for high strength sour service grades [16]. Retained austenite significantly increases the hydrogen solubility and decreases ductility of a hydrogen charged martensitic steel [17]. Failure due to hydrogen embrittlement can occur particularly when strain-induced martensite forms in austenite grains [18]. The freshly formed martensite then has a high concentration of hydrogen, which considerably facilitates cracking [19].

Thresholds for hydrogen contents that cause hydrogen embrittlement of specific steel grades are rare in the literature. Values for the amount of hydrogen absorbed in $\mathrm{H}_{2}$ gas at medium to high pressures are even more difficult to find. Nevertheless, several values for various steel grades and hydrogen charging conditions could be obtained from literature and are summarized in this publication.

Asahi et al. [20] found a critical hydrogen content of around $2.5 \mathrm{wt}$. ppm and $0.4 \mathrm{wt}$. ppm for martensitic steels with an ultimate tensile strength (UTS) of $1062 \mathrm{MPa}$ and $1212 \mathrm{MPa}$, respectively. Based on their results, they proposed equations to calculate the critical hydrogen concentration of any oil country tubular goods (OCTG) grade. For the martensitic steel grades L80 and P110, they calculated threshold hydrogen contents of $22.8 \mathrm{wt}$. ppm and $1.3 \mathrm{wt}$. ppm for embrittlement at room temperature. A yield strength (YS) of $765 \mathrm{MPa}$ results in a value of $8.2 \mathrm{wt}$. ppm. They also proposed an increasing hydrogen embrittlement threshold with increasing temperature. Peral et al. [21] tempered samples of the martensitic steel 42CrMo4 at two different temperatures and charged them with 195 bar $\mathrm{H}_{2}$ gas at $450{ }^{\circ} \mathrm{C}$ for $21 \mathrm{~h}$. The material tempered at a lower temperature had a YS of $1086 \mathrm{MPa}$, an UTS of $1200 \mathrm{MPa}$ and absorbed $1.9 \mathrm{wt}$. ppm hydrogen. The specimens tempered at a higher temperature $(\mathrm{YS}=622 \mathrm{MPa}$, UTS = $710 \mathrm{MPa})$ had a total hydrogen content of $1.2 \mathrm{wt}$. ppm after charging. Despite the high hydrogen concentration, the tensile properties of smooth specimens that were tested with slow strain rates remained practically unaffected. Tensile tests on notched specimens, however, showed a significant decrease in the UTS of the higher strength material. Hüter et al. [22] conducted slow strain rate tests on hydrogen charged, martensitic X20Cr13 with an UTS of $1046 \mathrm{MPa}$. At a hydrogen content of $5 \mathrm{wt}$. ppm they observed a brittle behaviour, while $1.5 \mathrm{wt}$. ppm (uncharged condition) resulted in a fracture surface with fully ductile features. Wang et al. [23] conducted constant load tests on notched AISI 4135 (34CrMo4) martensitic steel specimens that had previously been electrochemically charged. Tempering at two different temperatures had resulted in yield strengths of $1235 \mathrm{MPa}$ and $1320 \mathrm{MPa}$ and ultimate tensile strengths of $1320 \mathrm{MPa}$ and $1450 \mathrm{MPa}$. The higher strength material had a critical hydrogen concentration of $0.06 \mathrm{wt}$. ppm, the lower strength $0.2 \mathrm{wt}$. ppm. The load was $90 \%$ of the UTS. They found that the critical hydrogen concentration not only depends on the strength level, but also on the stress concentration factor determined by the geometry of the notch. The same authors tested un-notched tensile specimens of the lower strength material and found no significant change in the UTS, while the fracture elongation was reduced at a hydrogen content of $1.2 \mathrm{wt}$. ppm [24].

Todoshchenko et al. [25] conducted slow strain rate tests on hydrogen charged ASTM A106 Grade B (UTS $\cong 420 \mathrm{MPa}$ ). A hydrogen content of $1.11 \mathrm{wt}$. ppm resulted in a slightly increased tensile 
strength and a significantly reduced fracture elongation of the ferritic-pearlitic material. Revie et al. [26] tested various ferritic-bainitic linepipe steels in $\mathrm{H}_{2} \mathrm{~S}$-saturated buffered solution and found threshold hydrogen concentrations of 0.2 to $1.8 \mathrm{wt}$. ppm for hydrogen-induced cracking. Unfortunately, they did not specify the strength of the steel grades examined. Kittel et al. [27] performed HIC tests on linepipe steels similar to API 5L X65. Based on the results for five materials (YS $\cong 530 \mathrm{MPa}$, UTS $\cong 632 \mathrm{MPa}$ ) they proposed a critical hydrogen concentration of 0.8 to $1 \mathrm{wt}$. ppm for conventional ferritic-pearlitic steels. Others [28] found a threshold of $0.26 \mathrm{wt}$. ppm for the ferritic-pearlitic linepipe steel API 5L X60 (YS = $414 \mathrm{MPa}$ ). They performed $\mathrm{HIC}$ tests with $\mathrm{H}_{2} \mathrm{~S}$ and calculated the hydrogen content from permeation measurements. Kappes et al. [29] conducted permeation experiments on X65 in an $\mathrm{H}_{2} \mathrm{~S}$-saturated solution. A surface concentration of around $0.58 \mathrm{wt}$. ppm hydrogen significantly increased the fatigue crack growth rate of the steel (YS $=471 \mathrm{MPa})$. Hara et al. [30] proposed a critical hydrogen concentration of 0.3 to 2 wt. ppm for hydrogen induced cracking (HIC) initiation in X65 linepipe steel. They found differences in the behaviour of pearlitic and bainitic microstructures, the latter being much more resistant. Wang [31] found a critical hydrogen concentration of approximately 1 wt. ppm for the linepipe steel API X70. Above this limit, the fracture toughness of the material $(Y S=583 \mathrm{MPa})$ consisting of ferrite and degenerated pearlite decreases in a linear relationship with increasing hydrogen content. In so called small punch tests hydrogen gas with a pressure of only 0.5 bar is sufficient to trigger brittle behaviour of the ferritic-bainitic X70 pipeline steel [32]. The severe stress concentration conditions prevailing in these tests make it easier to reach the local critical hydrogen concentration. $3.6 \mathrm{wt}$. ppm of hydrogen add an additional tensile stress to X80 linepipe steel under external tension and therefore facilitate plastic deformation [33]. Meng et al. [34] performed slow strain rate tests on X80 pipeline steel (YS $=524 \mathrm{MPa}, \mathrm{UTS}=656 \mathrm{MPa})$ in $\mathrm{H}_{2} / \mathrm{N}_{2}$ mixtures at room temperature. While the strength and fracture elongation of smooth tensile specimens remained largely unaffected by the hydrogen gas up to a pressure of 60 bar, they observed a drop in the reduction of area between a hydrogen partial pressure of 12 and 24 bar. Six bar of $\mathrm{H}_{2}$ gas was sufficient to dramatically degrade the fatigue life. Even a hydrogen pressure of 300 bar did not influence the YS and the UTS of the ferritic-pearlitic X80 pipeline steel in slow strain rate tests, while a decrease of the fracture elongation was observed [35]. The embrittlement of the material (YS = 510 MPa) started at 1 bar, increased until a pressure of 50 bar and then stabilized [36]. Nagao et al. [37] charged the tempered martensitic steel API 5CT Q125 in 400 bar $\mathrm{H}_{2}$ gas at $200{ }^{\circ} \mathrm{C}$. They measured a hydrogen content of $0.8 \mathrm{wt}$. ppm in the material (YS = $911 \mathrm{MPa}$, UTS = $1001 \mathrm{MPa})$.

The pressure vessel steel 2.25Cr-1Mo absorbs $3 \mathrm{wt}$. ppm hydrogen when charged in 120 bar $\mathrm{H}_{2}$ gas at $420{ }^{\circ} \mathrm{C}$ [38]. The threshold for hydrogen embrittlement of the material (YS $\left.=475 \mathrm{MPa}, \mathrm{UTS}=614 \mathrm{MPa}\right)$ was found at $1.6 \mathrm{wt}$. ppm. Al-Rumaih and Gangloff [39] found a threshold of $1.4 \mathrm{wt}$. ppm for the bainitic $2.25 \mathrm{Cr}-1 \mathrm{Mo}$ (YS $\cong 530 \mathrm{MPa}$ ). No deterioration in the fracture resistance was observed below this value. Above the threshold it decreases dramatically [40]. A vanadium modified Cr-Mo steel of similar strength resists hydrogen embrittlement up to a hydrogen concentration of approximately 9 wt. ppm [41]. Álvarez et al. [42] charged the bainitic-martensitic 2.25Cr1Mo0.3V (YS = 590 MPa, $\mathrm{UTS}=700 \mathrm{MPa}$ ) in 195 bar $\mathrm{H}_{2}$ gas at $450{ }^{\circ} \mathrm{C}$ and measured a hydrogen content of $4.2 \mathrm{wt}$. ppm. The fracture surface of the single-edge notched tensile specimen was dominated by ductile features. Venezuela et al. [43] charged the 3.5NiCrMoV with 2, 20, 80 and 200 bar of $\mathrm{H}_{2}$ gas, which resulted in a hydrogen content of $0.57,0.64,0.87$ and $0.89 \mathrm{wt}$. ppm. The charging took $24 \mathrm{~h}$, the first two hours at $200{ }^{\circ} \mathrm{C}$ and then cooling to room temperature in the turned off furnace. The quenched-and-tempered, martensitic steel had a YS of $661 \mathrm{MPa}$ and an UTS of $782 \mathrm{MPa}$. Even electrochemically generated hydrogen concentrations of up to $1.93 \mathrm{wt}$. ppm, which correspond to hydrogen fugacities of over a thousand bar, did not affect the ductility of this steel when tested in linearly increasing stress tests, although brittle areas were observed on the fracture surface $[43,44]$. With cathodic charging, AISI 4340 (36CrNiMo4) has a saturation value of approximately 5 to $8 \mathrm{wt}$. ppm [45,46]. In 1.1 bar $\mathrm{H}_{2}$ gas at room temperature Bandyopadhyay et al. [47] calculated a hydrogen content of $0.01 \mathrm{wt}$. ppm for the martensitic steel (YS = $1138 \mathrm{MPa}$ ). Das et al. [48] simulated hydrogen charged notched AISI 4340 bars 
$(\mathrm{YS}=1270 \mathrm{MPa})$ in four-point bending tests and found a threshold hydrogen concentration for the brittle to ductile transition of $0.02 \mathrm{wt}$. ppm. Garrison and Moody [49] reported decreasing threshold stress intensity factors with increasing hydrogen pressure and increasing YS of AISI 4340.

Based on the research of Scharf et al. [50] a hydrogen content of approximately $1.2 \mathrm{wt}$. ppm is sufficient to cause embrittlement of a ferritic-martensitic high-strength dual-phase steel that is loaded at $80 \%$ of its YS. A hydrogen content of $1.5 \mathrm{wt}$. ppm causes a significant deterioration of the fracture elongation of a quenching \& partitioning treated high strength steel (YS $=746 \mathrm{MPa}, \mathrm{UTS}=1013 \mathrm{MPa})$ [51] Lovicu et al. [19] investigated two martensitic high-strength steels (YS = $1205 \mathrm{MPa}$, UTS $=1305 \mathrm{MPa}$ and YS $=1410 \mathrm{MPa}$, UTS $=1520 \mathrm{MPa}$ ). They reported a critical hydrogen concentration of about 4 wt. ppm for the former and about 1 wt. ppm for the latter. Kim et al. [52] found a clear dependence of the susceptibility to hydrogen embrittlement of high-strength steels on the microstructure. For a fully pearlitic steel with an UTS of slightly over $1600 \mathrm{MPa}$ they found a critical hydrogen content of around $0.42 \mathrm{wt}$. ppm. The same steel with a tempered martensitic microstructure and the same strength showed hydrogen embrittlement from a hydrogen concentration of 0.07 to $0.20 \mathrm{wt}$. ppm. Thomas et al. [53] reported a significant and continuous decrease in threshold stress intensity of an ultrahigh-strength martensitic steel (YS = $1765 \mathrm{MPa}$, UTS $=1985 \mathrm{MPa}$ ) between $0.3 \mathrm{wt}$. ppm (uncharged condition) and $10 \mathrm{wt}$. ppm. When loaded with its YS of more than $2000 \mathrm{MPa}$, the bainitic high-strength steel UNS G10700 (Ck67) shows hydrogen embrittlement from a hydrogen content of $1.5 \mathrm{wt}$. ppm. For the molybdenum-modified version with same strength and microstructure, $0.7 \mathrm{wt}$. ppm hydrogen are sufficient to cause cracking [54].

The ferritic-austenitic duplex stainless steel 2205 absorbs 0.83 wt. ppm hydrogen when charged in 100 bar $\mathrm{H}_{2}$ gas at $80^{\circ} \mathrm{C}$. The addition of an aqueous electrolyte results in a significantly higher uptake. Nevertheless, with a constant load of $90 \%$ of the specified minimum yield strength (SMYS), the hydrogen content is not sufficient to cause embrittlement [55]. Takai et al. [56] charged the austenitic stainless steel SUS 316L in hydrogen gas with various pressures at $90^{\circ} \mathrm{C} .100$ bar resulted in a hydrogen content of 9 wt. ppm, 200 bar in $20 \mathrm{wt}$. ppm and 450 bar in $39 \mathrm{wt}$. ppm. The amount of hydrogen absorbed by austenitic steels is not only significantly higher than the amount absorbed by carbon steels, but also the amount of hydrogen required to initiate embrittlement is one or two orders of magnitude greater than that of steels with bcc lattice [57].

The aim of the presented work is to generate data on the hydrogen uptake of three carbon steels under seven different conditions at two temperatures and to check whether hydrogen embrittlement occurs.

\section{Materials and Methods}

Carbon steels that are commonly used in the oil and gas industry were investigated: L80 Type 1, P110 (both according to API 5CT [16]) and 42CrMo4 (UNS G41400). Samples were taken from commercially available casing tube sections. The chemical composition of the materials investigated is given in Table 1.

Table 1. Chemical composition of the investigated materials (wt.\%).

\begin{tabular}{ccccccccccc}
\hline Material & C & Si & Mn & P & S & Cu & Cr & Ni & Mo & Fe \\
\hline L80 & 0.33 & 0.21 & 1.38 & 0.017 & 0.009 & 0.02 & 0.25 & 0.02 & 0.01 & bal. \\
42CrMo4 & 0.42 & 0.27 & 0.85 & 0.014 & 0.012 & 0.01 & 1.01 & 0.02 & 0.17 & bal. \\
P110 & 0.31 & 0.21 & 1.36 & 0.011 & 0.007 & 0.02 & 0.24 & 0.02 & 0.01 & bal. \\
\hline
\end{tabular}

The mechanical properties of the tested materials are given in Table 2. The values were obtained in tensile tests performed in air on small, non-standard tensile specimens with an initial gauge length of $25 \mathrm{~mm}$ and a circular cross section with a diameter of $3 \mathrm{~mm}$. The strain rate was $6.7 \times 10^{-5} \mathrm{~s}^{-1}$. 
Table 2. Specified minimum yield strength (SMYS), yield strength (YS), ultimate tensile strength (UTS) and fracture elongation (A) of the investigated materials.

\begin{tabular}{cccccccc}
\hline Material & $\begin{array}{c}\text { SMYS } \\
\mathbf{( M P a )}\end{array}$ & $\begin{array}{c}\text { SMYS } \\
\mathbf{( k s i )}\end{array}$ & $\begin{array}{c}\text { YS } \\
\mathbf{( M P a})\end{array}$ & $\begin{array}{c}\text { YS } \\
\mathbf{( k s i )}\end{array}$ & $\begin{array}{c}\text { UTS } \\
\mathbf{( M P a})\end{array}$ & $\begin{array}{c}\text { UTS } \\
\mathbf{( k s i )}\end{array}$ & $\begin{array}{c}\text { A } \\
\mathbf{( \% )}\end{array}$ \\
\hline L80 & 552 & 80 & 607 & 88 & 721 & 105 & 17.3 \\
$42 \mathrm{CrMo} 4$ & 750 & 109 & 765 & 111 & 1014 & 147 & 12.1 \\
P110 & 758 & 110 & 921 & 134 & 1015 & 147 & 8.4 \\
\hline
\end{tabular}

The investigated materials can be assigned to three different strength levels, with L80 having the lowest yield strength, P110 having the highest and 42CrMo4 lying in the middle. The ultimate tensile strength is the same for $42 \mathrm{CrMo} 4$ and P110, while the L80 is lower. Figure 1 shows the microstructure of the examined steel grades.

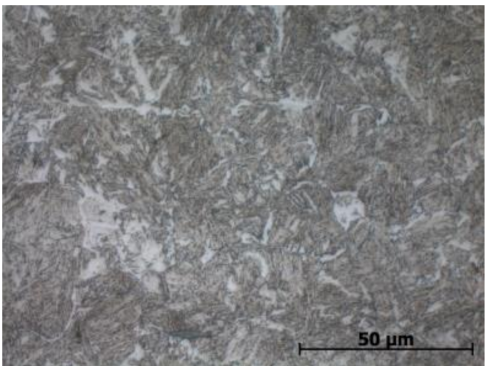

(a)

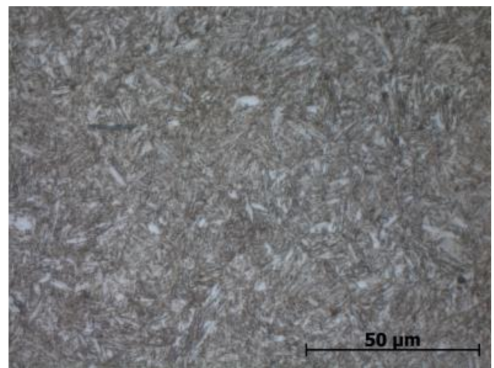

(b)

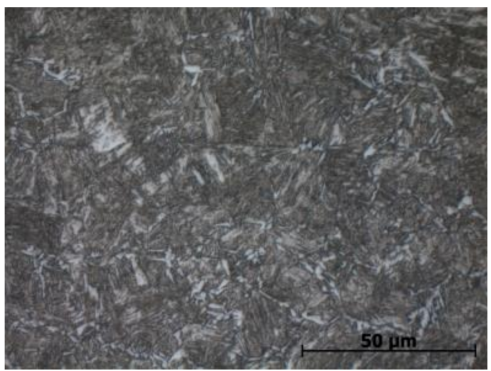

(c)

Figure 1. Microstructure of the investigated materials: (a) L80; (b) 42CrMo4; (c) P110.

All three materials have a microstructure of tempered martensite. Former austenite grains have a size of 20 to $40 \mu \mathrm{m}$, which is fine. The microstructure of $42 \mathrm{CrMo} 4$ is somewhat finer than that of the other two materials. The volume fraction of retained austenite was determined by means of X-ray diffraction with Mo K $\alpha$ radiation in a 'Bruker D8 DISCOVER' in accordance with ASTM standard E975-13 [58]. The samples were wet ground with silicon carbide paper (grit 120, 320 and 500) and a $150 \mu \mathrm{m}$ thick layer was electrochemically removed prior to analysis. The amount of retained austenite in all three materials was below the detection limit of $1 \%$ specified in the standard. Two types of specimens were tested: Immersion specimens were cuboids with a square base (edge length of $6 \mathrm{~mm}$ ) and a height of $30 \mathrm{~mm}$. The small tensile specimens for the constant load tests (CLTs) were the same as for the tensile tests in air mentioned earlier. The load of $90 \%$ of the specified minimum yield strength (SMYS) was applied to the respective CLT specimen with a spring made of a cobalt-base alloy and ceramic nuts, the latter ensuring electronic decoupling of the specimen from the more noble spring. All specimens were tested in the as-machined condition. Prior to testing, the specimens were cleaned in an ultrasonic bath with acetone.

Two different types of tests were conducted: autoclave tests at elevated pressure and tests at ambient pressure. For the former, the installation of specimens within the autoclave is shown schematically in Figure 2.

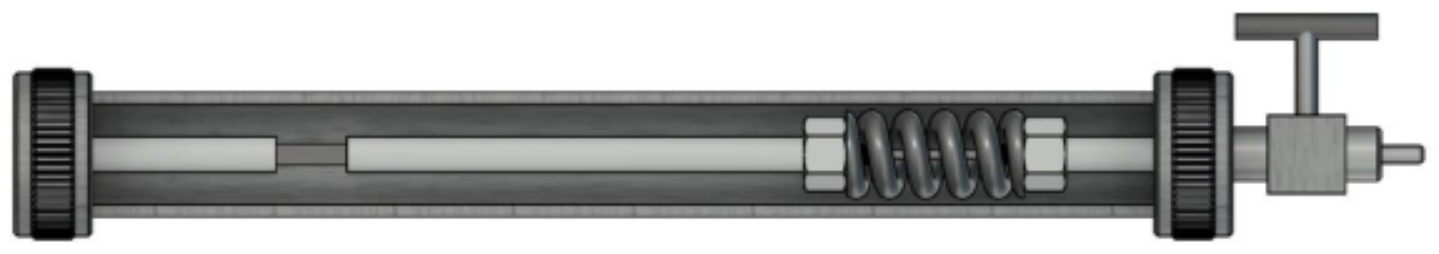

Figure 2. Experimental setup of the autoclave tests (schematic). 
The immersion specimen (left) and the CLT specimen (right) were held in place by polytetrafluoroethylene (PTFE) parts. Tests were conducted under anaerobic conditions with $\mathrm{H}_{2}$ gas at partial pressures of 20 and 100 bar. In addition, the influence of 5 bar $\mathrm{CO}_{2}$ gas was investigated. The autoclave tests were divided into tests with and without electrolyte, which are referred to as wet and dry conditions. The electrolyte (brine) was an aqueous $\mathrm{NaCl}$ solution with a chloride concentration of $15,000 \mathrm{ppm}$. The tests were carried out at $25^{\circ} \mathrm{C}$ as well as $80^{\circ} \mathrm{C}$ and lasted 30 days. The autoclaves were rotated with a speed of $1 \mathrm{RPM}$. Consequently, the specimens were periodically wetted with the brine, if any. The test procedure is described in detail elsewhere $[59,60]$. The experimental setup of the tests at ambient pressure is shown schematically in Figure 3. The geometry and handling of the specimens was the same as for the autoclave tests. The medium for the tests at ambient pressure was the 'Solution A' described in the NACE standard TM0177 [61]. This is an acidified $\mathrm{H}_{2} \mathrm{~S}$-saturated aqueous brine solution with $5.0 \mathrm{wt} . \% \mathrm{NaCl}$ and $0.5 \mathrm{wt} . \% \mathrm{CH}_{3} \mathrm{COOH}$. The tests were conducted at room temperature and lasted 14 days.

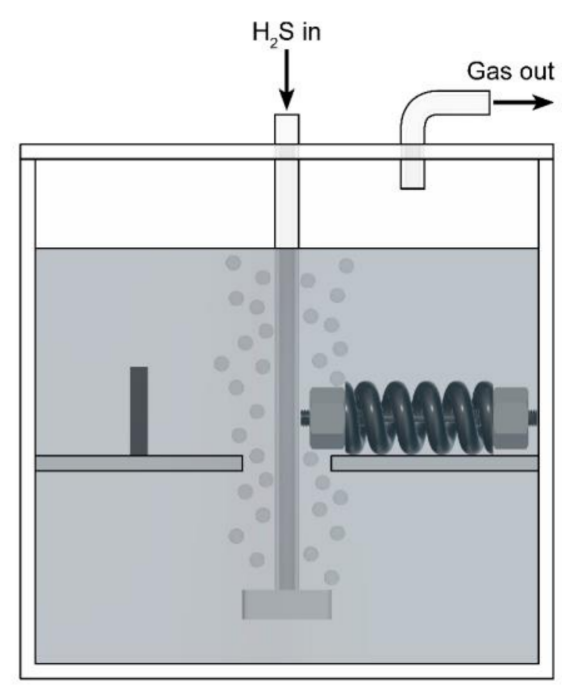

Figure 3. Experimental setup of the tests at ambient pressure (schematic).

After the autoclave tests, the immersion specimens were removed from the vessels and immediately cooled in liquid nitrogen. Specimens immersed at ambient pressure were removed after different times of charging in $\mathrm{H}_{2} \mathrm{~S}$ and instantly cooled in liquid nitrogen too. The cooled specimens were ground with silicon carbide paper (grit 120) to remove corrosion products. The sides of the specimens were ground individually and after grinding each side of the specimens they were again cooled in liquid nitrogen. The specimens were never outside the liquid nitrogen for more than $15 \mathrm{~s}$ at a time. Before the hydrogen analysis was done, each specimen was rinsed with acetone, dried with a cold air fan, and weighed. The time between the removal from the liquid nitrogen and the start of the analysis in the furnace was less than $60 \mathrm{~s}$. The hydrogen content was measured in an ELTRA H-500 (ELTRA GmbH, Haan, Germany) analyser after carrier gas hot extraction at $950{ }^{\circ} \mathrm{C}$. The extracted hydrogen results in an increase of thermal conductivity of the carrier gas (pure nitrogen), expressed as a voltage peak as a function of time. The integral of the peak is a measure of the hydrogen extracted from the specimen. Calibration was done twice with calibration gas and gold-coated calibration standards. At the end of the autoclave tests and periodically during the $\mathrm{H}_{2} \mathrm{~S}$ tests, the constant load specimens were checked for possible fractures.

\section{Results}

Each material was tested under seven different conditions. Selected conditions were tested up to three times. Since a maximum deviation of $\pm 15 \%$ was found, all error bars show this value. 


\subsection{Hydrogen Analyses}

Results for the hydrogen content of immersion specimens made of L80, which were tested in autoclaves under increased pressure, are given in Figure 4.

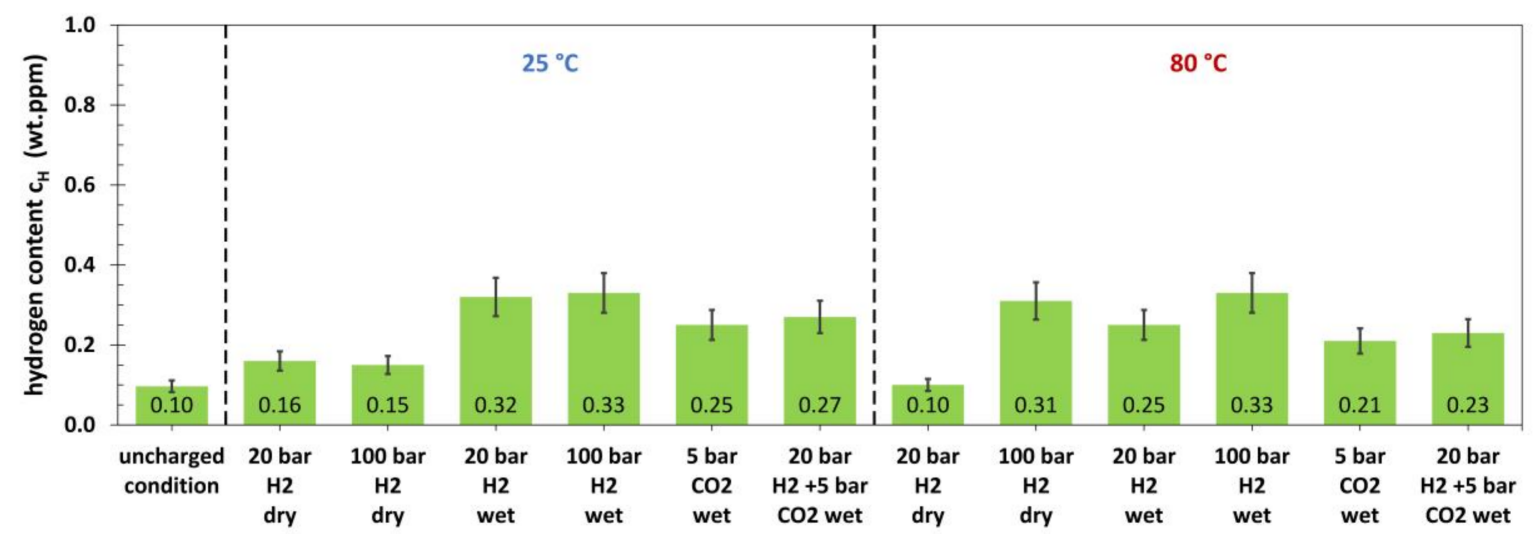

Figure 4. Hydrogen content of L80 after 30 days of autoclave testing with various media at $25^{\circ} \mathrm{C}$ and $80{ }^{\circ} \mathrm{C}$ (wet conditions: with electrolyte; $15,000 \mathrm{ppm} \mathrm{Cl}^{-}$).

In the uncharged condition, a hydrogen content of $0.10 \mathrm{wt}$. ppm was measured. Dry $\mathrm{H}_{2}$ gas with a pressure of 20 and 100 bar did not lead to significant amounts of absorbed hydrogen at $25^{\circ} \mathrm{C}$. At $80^{\circ} \mathrm{C}$, 20 bar dry $\mathrm{H}_{2}$ gas was not sufficient to cause a higher hydrogen content than in the uncharged state, whereas a total hydrogen content of $0.31 \mathrm{wt}$. ppm was measured after charging in 100 bar. The presence of brine (wet conditions) promoted the hydrogen absorption in high pressure $\mathrm{H}_{2}$ gas atmospheres at both temperatures tested and a maximum hydrogen content of $0.33 \mathrm{wt}$. ppm was measured. $\mathrm{CO}_{2}$ gas increased the hydrogen content of the immersion specimens without the presence of $\mathrm{H}_{2}$ gas and a maximum of $0.25 \mathrm{wt}$. ppm was found after testing at $25^{\circ} \mathrm{C}$. The mixture of the two gases resulted in a hydrogen uptake that was slightly above the level of the conditions with only $\mathrm{CO}_{2}$ gas. Figure 5 shows the measured hydrogen content for the $42 \mathrm{CrMo} 4$ after autoclave testing.

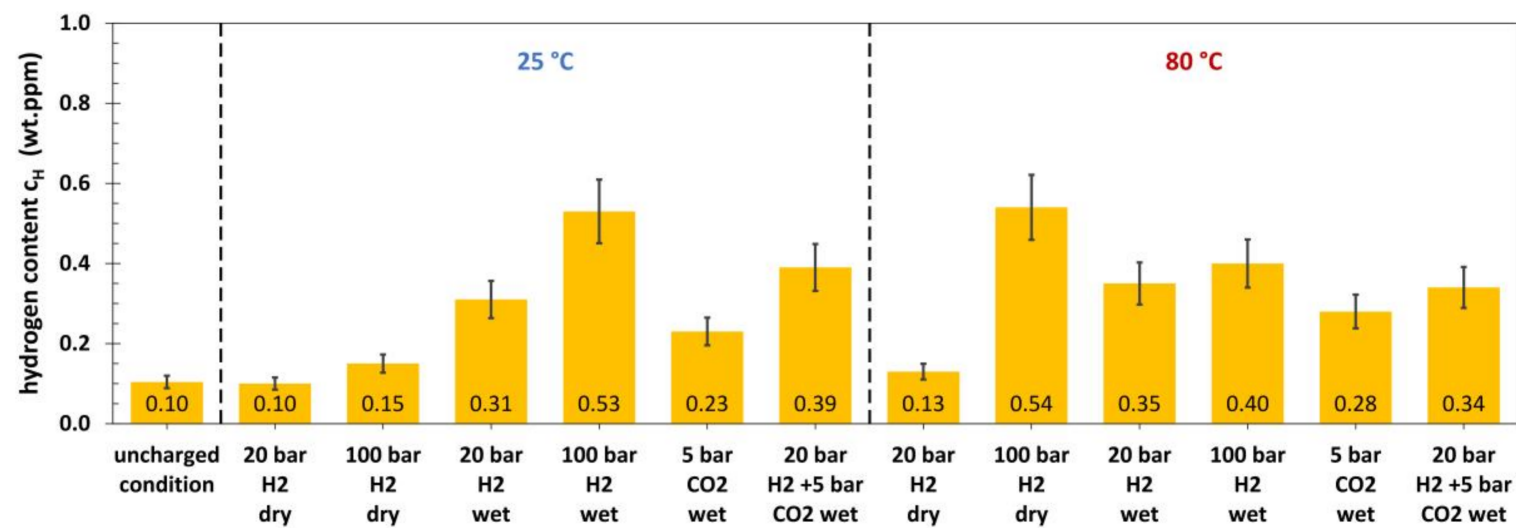

Figure 5. Hydrogen content of $42 \mathrm{CrMo} 4$ after 30 days of autoclave testing with various media at $25^{\circ} \mathrm{C}$ and $80{ }^{\circ} \mathrm{C}$ (wet conditions: with electrolyte; $15,000 \mathrm{ppm} \mathrm{Cl}^{-}$).

Like for the L80, the hydrogen content of 42CrMo4 (Figure 5) in the uncharged condition was 0.10 wt. ppm. At $25^{\circ} \mathrm{C}$, dry $\mathrm{H}_{2}$ gas with a pressure of 20 and 100 bar did not cause any significant hydrogen absorption. The same was true for 20 bar dry $\mathrm{H}_{2}$ gas at $80{ }^{\circ} \mathrm{C}$, whereas 100 bar resulted in a total hydrogen content of $0.54 \mathrm{wt}$. ppm. Wet conditions with $\mathrm{H}_{2}$ gas promoted hydrogen absorption at 25 and $80{ }^{\circ} \mathrm{C}$. The hydrogen content measured after autoclave tests on $42 \mathrm{CrMo} 4$ with $\mathrm{CO}_{2}$ gas was 
comparable to the results obtained for the L80 under the same conditions. The gas mixture also clearly caused an increase in hydrogen absorption. The results for P110 are shown in Figure 6.

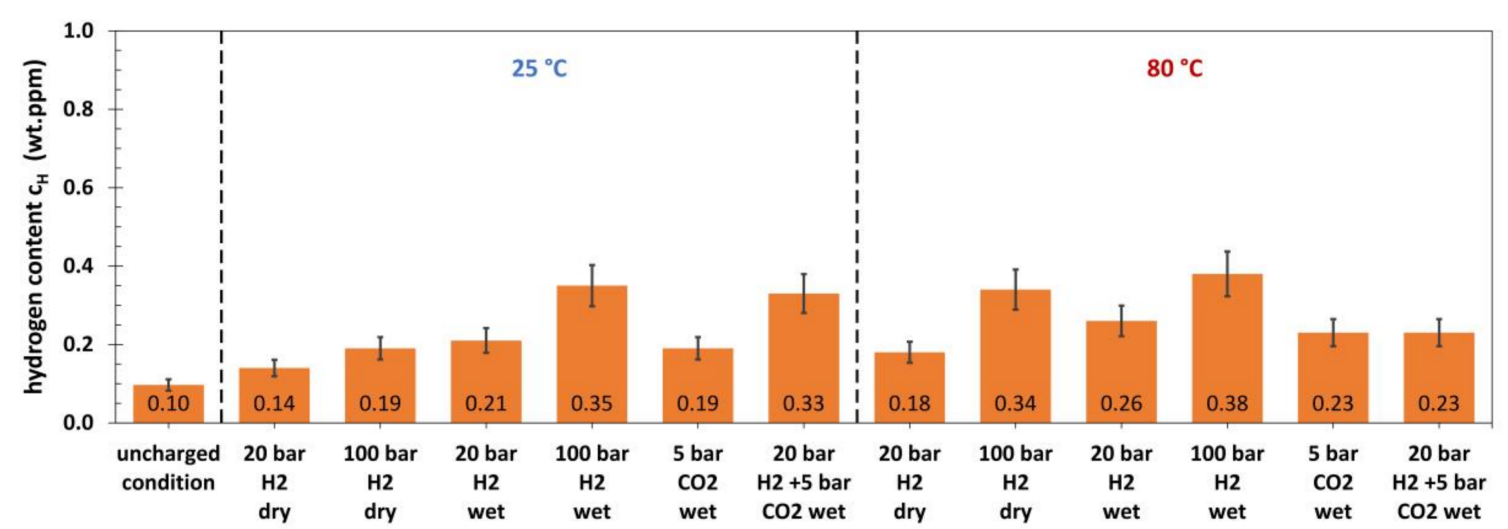

Figure 6. Hydrogen content of P110 after 30 days of autoclave testing with various media at $25^{\circ} \mathrm{C}$ and $80{ }^{\circ} \mathrm{C}$ (wet conditions: with electrolyte; $15,000 \mathrm{ppm} \mathrm{Cl}^{-}$).

Without charging, the P110 had a total hydrogen content of 0.10 wt. ppm, which corresponds to the other two materials tested. Of the dry conditions, only the combination of $100 \mathrm{bar}_{2}$ gas and $80^{\circ} \mathrm{C}$ resulted in a hydrogen content that was significantly higher than that of the uncharged condition, while the others at least resulted in an increased content. This behaviour is similar to that of $\mathrm{L} 80$ and $42 \mathrm{CrMo} 4$. The combination of electrolyte and $\mathrm{H}_{2}$ gas promoted the hydrogen absorption at both temperatures tested and a maximum hydrogen content of $0.38 \mathrm{wt}$. ppm was measured. $\mathrm{CO}_{2}$ gas also increased the hydrogen content of the P110 immersion specimens, as was the case with the other two materials tested. The mixture of the two gases caused an increase in hydrogen absorption, this behaviour being much more pronounced at $25^{\circ} \mathrm{C}$ than at $80^{\circ} \mathrm{C}$. Figures 7 and 8 show the results of the hydrogen analyses on specimens charged at ambient pressure.

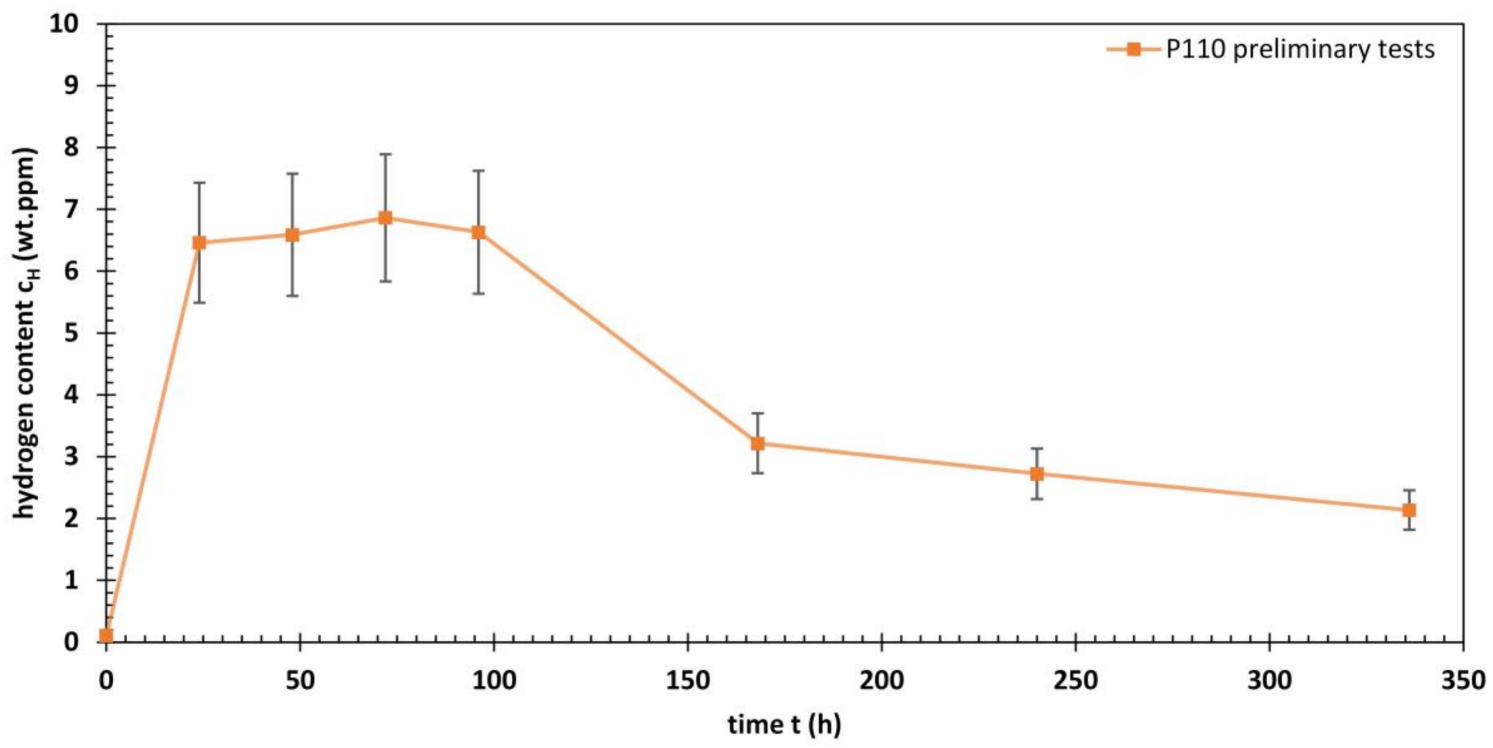

Figure 7. Hydrogen content of P110 after various times of ambient pressure testing in an acidified $\mathrm{H}_{2} \mathrm{~S}$-saturated aqueous brine solution with $5.0 \mathrm{wt} . \% \mathrm{NaCl}$ and $0.5 \mathrm{wt} . \% \mathrm{CH}_{3} \mathrm{COOH}$ at room temperature (NACE Solution A). 


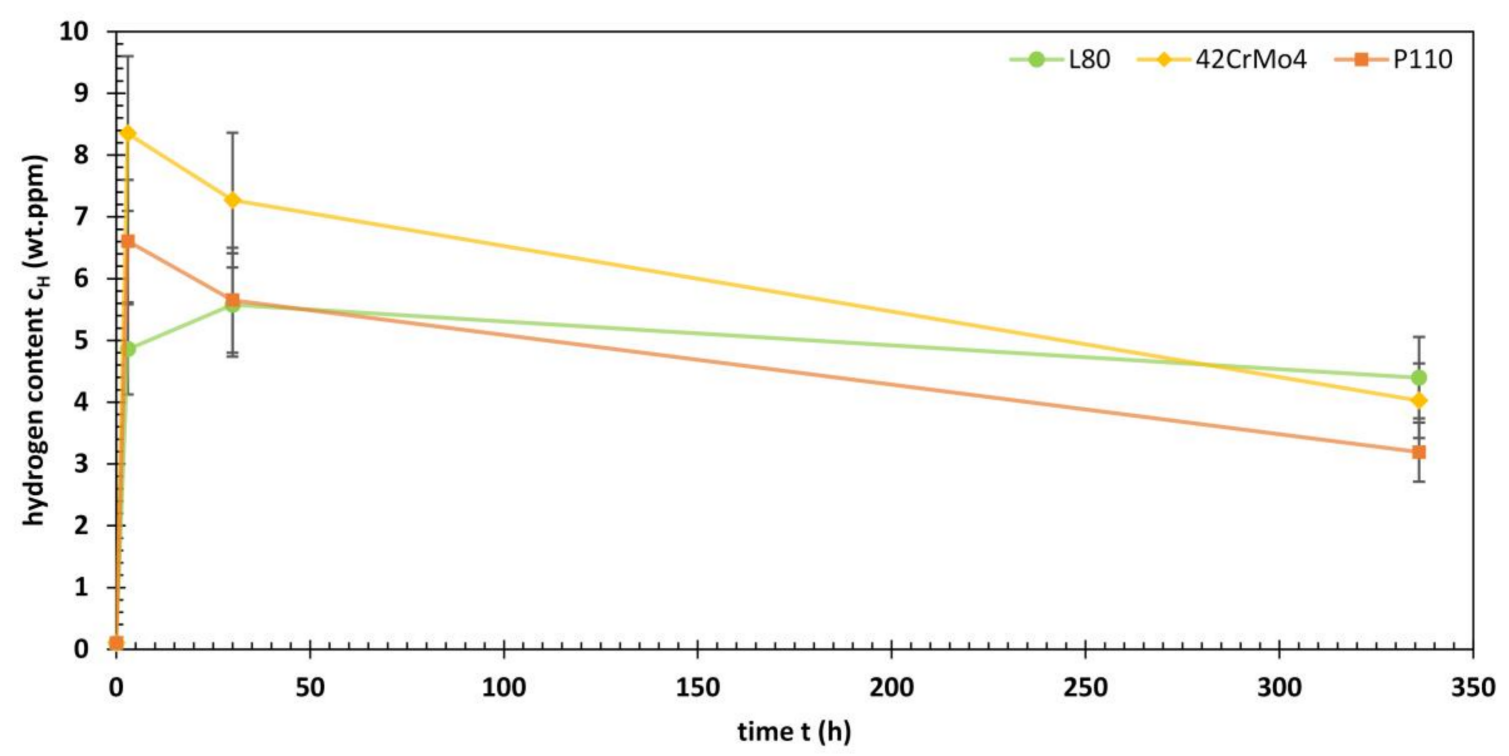

Figure 8. Hydrogen content of L80, 42CrMo4 and P110 after 3, 30 and $336 \mathrm{~h}$ of ambient pressure testing in an acidified $\mathrm{H}_{2} \mathrm{~S}$-saturated aqueous brine solution with $5.0 \mathrm{wt} . \% \mathrm{NaCl}$ and $0.5 \mathrm{wt} . \% \mathrm{CH}_{3} \mathrm{COOH}$ at room temperature (NACE Solution A).

When steel is immersed in an acidified $\mathrm{H}_{2} \mathrm{~S}$-saturated aqueous brine solution, the conditions of hydrogen charging may change over time due to the formation of a corrosion product layer and slight variations in $\mathrm{pH} . \mathrm{H}_{2} \mathrm{~S}$ tests were conducted on similar specimens made of $\mathrm{P} 110$ to determine the hydrogen content as a function of time. The results of these tests are shown in Figure 7. The hydrogen content shows a plateau during the first days of immersion in NACE Solution A and a decrease towards the end of the test. This behaviour can be explained by the formation of a corrosion product layer. The scale consisting of iron sulfides reduces the further corrosion rate and thus the number of hydrogen atoms generated for possible absorption. The layer may not reduce hydrogen effusion to the same extent. The results for the hydrogen content of L80, 42CrMo4 and P110 after various times of ambient pressure testing in acidified $\mathrm{H}_{2} \mathrm{~S}$-saturated aqueous brine solution are shown in Figure 8 .

Prior to the immersion in NACE Solution A, all three materials tested had a hydrogen content of 0.10 wt. ppm. After three hours of testing, the first specimens were removed from the solution and hydrogen analyses indicated significant amounts of absorbed hydrogen. The total hydrogen contents for L80, 42CrMo4 and P110 were 4.86, 8.35 and $6.61 \mathrm{wt}$. ppm. In the following $27 \mathrm{~h}$, the value for L80 further increased to $5.58 \mathrm{wt}$. ppm, while those for $42 \mathrm{CrMo} 4$ and P110 decreased to 7.27 and $5.65 \mathrm{wt}$. ppm. At the end of the test ( $336 \mathrm{~h}$ ) a hydrogen content of 4.40, 4.03 and $3.19 \mathrm{wt}$. ppm was measured for L80, 42CrMo4 and P110. A look at the shape of the curves shown in Figure 8 reveals a similarity between those for $42 \mathrm{CrMo} 4$ and $\mathrm{P} 110$, the latter is shifted to lower hydrogen contents. The maximum hydrogen content for both materials was measured after three hours of $\mathrm{H}_{2} \mathrm{~S}$ testing. The $\mathrm{L} 80$ with its maximum after $30 \mathrm{~h}$ contrasts this trend.

\subsection{Constant Load Tests}

None of the specimens constantly loaded at $90 \%$ of the SMYS broke under the conditions tested in the autoclaves (up to 100 bar $\mathrm{H}_{2}$ gas). None of the unbroken specimens showed visible cracks under the stereo microscope. Figure 9 shows the results of the CLTs in NACE Solution A at ambient pressure. The dashed line represents the end of the test after 14 days. 


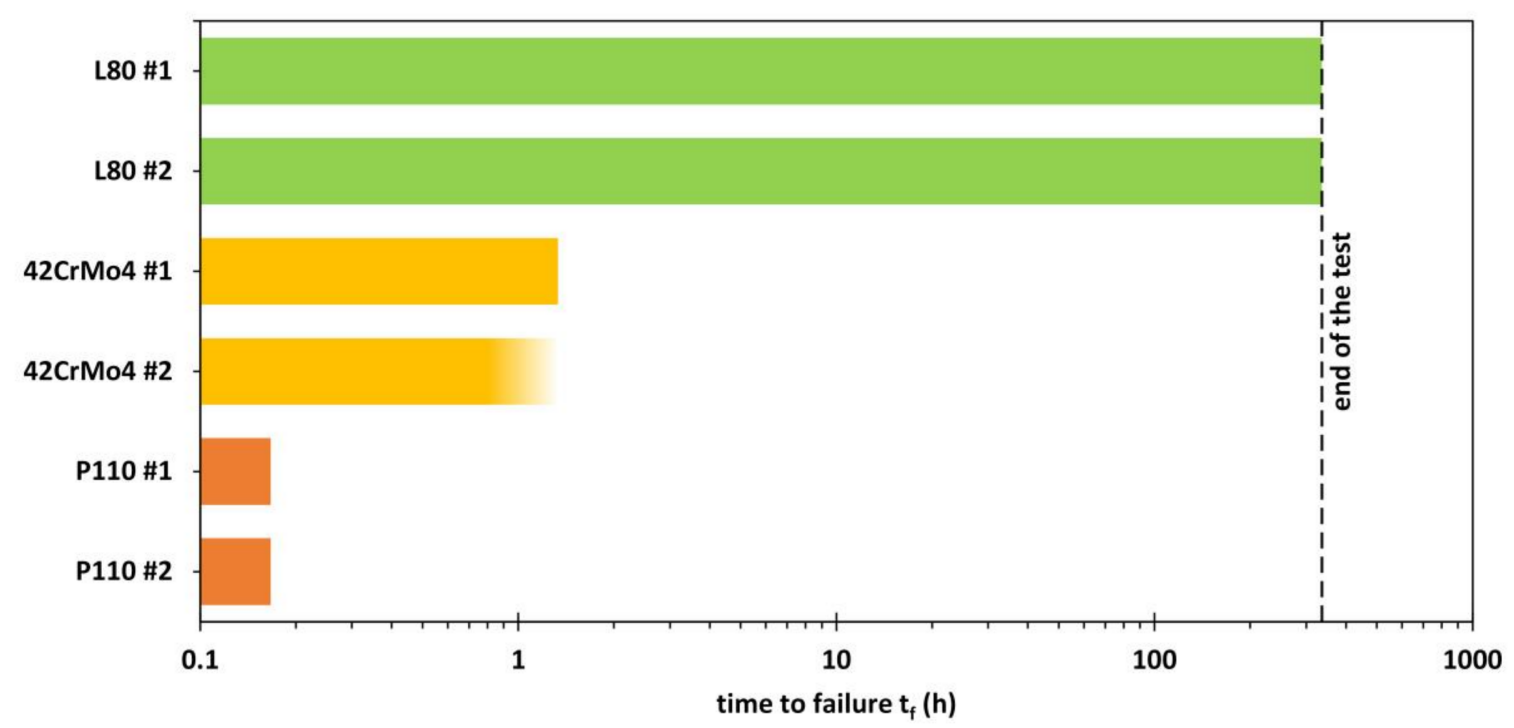

Figure 9. Results of the CLTs at $90 \%$ of the SMYS in acidified $\mathrm{H}_{2} \mathrm{~S}$-saturated aqueous brine with 5.0 wt. $\%$ $\mathrm{NaCl}$ and $0.5 \mathrm{wt} . \% \mathrm{CH}_{3} \mathrm{COOH}$ at room temperature (NACE Solution A). The bar with a blurred end represents a failure where time is not exactly known.

The first specimens to fail in $\mathrm{H}_{2} \mathrm{~S}$ were those made of P110. These were broken after only ten minutes of immersion. They were followed by the $42 \mathrm{CrMo} 4$, failing after slightly less than $80 \mathrm{~min}$ and after 80 min respectively. None of the specimens made of L80 failed in NACE Solution A during the $336 \mathrm{~h}$ of testing.

\section{Discussion}

The hydrogen analyses on specimens tested in autoclaves gave results, which indicate an overall low but still detectable hydrogen absorption. The values for hydrogen uptake presented in this work are in good agreement with findings from the literature where similar steel grades were charged in $\mathrm{H}_{2}$ gas $[21,37,38,42,43]$. Fluctuations in the total hydrogen content after autoclave tests under different conditions can be attributed to different causes. According to Sieverts and Krumbhaar [4] the partial pressure of hydrogen gas has a strong influence on the amount of hydrogen absorbed by iron. This dependency was found for to all three steels tested, being most pronounced in dry conditions at $80^{\circ} \mathrm{C}$.

The presence of electrolyte promoted hydrogen uptake from $\mathrm{H}_{2}$ gas at $25^{\circ} \mathrm{C}$. Since the specimens still had a metallic lustre after the test, the influence of corrosion on the hydrogen absorption can be neglected. Nevertheless, the specimens tested under wet conditions with $\mathrm{H}_{2}$ gas looked slightly tarnished and therefore some corrosion may have occurred. With 20 bar $\mathrm{H}_{2}$ gas at $80^{\circ} \mathrm{C}$ the presence of brine also led to a higher hydrogen content of all tested materials. Under the same conditions, with the exception of a higher pressure ( $100 \mathrm{bar}_{2}$ ), this behaviour was not found for the $42 \mathrm{CrMo} 4$, while L80 and P110 behaved the same way as already observed at 20 bar. An explanation for the comparatively high hydrogen content ( $0.54 \mathrm{wt}$. ppm) of $42 \mathrm{CrMo} 4$ after autoclave testing with 100 bar dry $\mathrm{H}_{2}$ gas at $80{ }^{\circ} \mathrm{C}$ cannot be given. It is assumed that this slightly higher content compared to 100 bar wet $\mathrm{H}_{2}$ lies within the scatter of hydrogen analysis.

Conditions with $\mathrm{CO}_{2}$ gas resulted in uniform corrosion of the immersion specimens. A dark grey scale was observed. It can be concluded from the cleaning of additionally tested specimens in hydrochloric acid that the layer consisted of iron(II) carbonate $\mathrm{FeCO}_{3}$ (siderite). The $\mathrm{CO}_{2}$ corrosion led to hydrogen absorption. The addition of $20 \mathrm{bar}_{2}$ gas further increased the hydrogen content. Although corrosion already is considered critical regarding hydrogen embrittlement, $100 \mathrm{bar}_{2}$ gas can lead to even higher hydrogen contents than corrosive environments with $\mathrm{CO}_{2}$ gas. 
At $80^{\circ} \mathrm{C}$, the investigated materials tend to absorb more hydrogen, when exposed to dry $\mathrm{H}_{2}$ gas than at $25^{\circ} \mathrm{C}$. This observation is in line with Sieverts' law, according to which the hydrogen solubility in metals increases with temperature. Under wet conditions, additional factors may influence the temperature dependence of the amount of hydrogen absorbed. The solubility of gases in brine generally decreases with temperature while chemical reaction rates (e.g., in the event of corrosion) double with each $10^{\circ} \mathrm{C}$. The temperature dependence of the hydrogen uptake under conditions with $\mathrm{CO}_{2}$ gas may be influenced by a change in morphology of the corrosion product film. Above $65^{\circ} \mathrm{C}$ a more protective corrosion product layer is formed [62]. Overall, the results show no significant temperature influence on the hydrogen absorption of the carbon steels that were tested in autoclaves under wet conditions.

The hydrogen contents measured after the ambient pressure tests with $\mathrm{H}_{2} \mathrm{~S}$ were significantly higher than those found in the autoclave tests without $\mathrm{H}_{2} \mathrm{~S}$. Corrosion and inhibition of recombination of hydrogen atoms to $\mathrm{H}_{2}$ molecules due to $\mathrm{H}_{2} \mathrm{~S}$ promoted hydrogen absorption. Initially higher corrosion rates and formation of a somewhat protective iron sulfide layer during the immersion led to high hydrogen contents at the beginning of the test with a decrease towards the end. In general, the amount of hydrogen absorbed under conditions with $\mathrm{H}_{2} \mathrm{~S}$ is approximately one order of magnitude

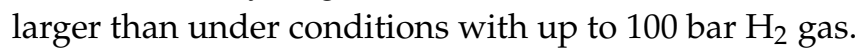

A higher defect density and the increase in strength leads to a higher number of hydrogen traps. Regarding the maximum hydrogen content measured after autoclave tests with $\mathrm{H}_{2}$ gas as well as ambient pressure tests with $\mathrm{H}_{2} \mathrm{~S}$, the higher strength $\mathrm{P} 110$ absorbed more hydrogen than the lower strength L80. The 42CrMo4 has the same UTS and even a lower YS than the P110 but absorbed slightly more hydrogen during both types of tests. This behaviour can be explained by the somewhat finer microstructure of $42 \mathrm{CrMo} 4$, which offers more interfaces that serve as possible hydrogen traps. Since the volume fraction of retained austenite in the microstructure of all three materials tested is less than $1 \%$, its influence on the trapping of hydrogen can be neglected.

In ambient pressure tests with $\mathrm{H}_{2} \mathrm{~S}$ for the materials $42 \mathrm{CrMo} 4$ and $\mathrm{P} 110$ the maximum hydrogen content was measured after three hours. The L80 with its maximum measured after $30 \mathrm{~h}$ seems to be lagging behind. A possible explanation could be a slower corrosion rate with an associated lower hydrogen generation. Occasional visual inspections during the experiment have indeed shown that the formation of the corrosion product layer on the L80 was slightly retarded compared to the other materials. This effect could be attributed to fewer defects in the lower strength material.

The hydrogen content reached in the autoclave tests with up to $100 \mathrm{bar}_{2}$ gas was not sufficient to cause hydrogen embrittlement leading to failures of tensile specimens under a constant load of $90 \%$ of the SMYS. Ambient pressure conditions with $\mathrm{H}_{2} \mathrm{~S}$ resulted in a failure of $\mathrm{P} 110$ after only ten minutes of immersion. Since a hydrogen content of $6.61 \mathrm{wt}$. ppm was measured $170 \mathrm{~min}$ after the failure in $\mathrm{H}_{2} \mathrm{~S}$ and 0.38 wt. ppm was not sufficient for a failure in $\mathrm{H}_{2}$ gas, the threshold value for hydrogen embrittlement lies somewhere in between. This is in agreement with the findings of Asahi et al. [20], where a critical hydrogen content of $1.3 \mathrm{wt}$. ppm is proposed for the P110. Simultaneously, the threshold for $42 \mathrm{CrMo} 4$ is between $0.54 \mathrm{wt}$. ppm and $8.35 \mathrm{wt}$. ppm. The equation postulated by Asahi et al. [20] can be used to calculate a limit of $8.2 \mathrm{wt}$. ppm for this material.

Since the specimens made from L80 did not fail under a constant load of $90 \%$ of the SMYS, although a maximum hydrogen content of $5.58 \mathrm{wt}$. ppm was found, the threshold concentration for hydrogen embrittlement is greater than this value. This is in accordance with the findings from the literature, where a critical hydrogen content of $22.8 \mathrm{wt}$. ppm was proposed [20]. In the present work, the maximum hydrogen content measured after immersion in up 100 bar $\mathrm{H}_{2}$ gas was 0.33 wt. ppm and thus significantly lower. The sour service steel grade L80 is therefore suitable for application under the tested conditions with up to 100 bar $\mathrm{H}_{2}$ gas. The critical hydrogen contents for embrittlement found in this work are compared with data from the literature in Figure 10. 


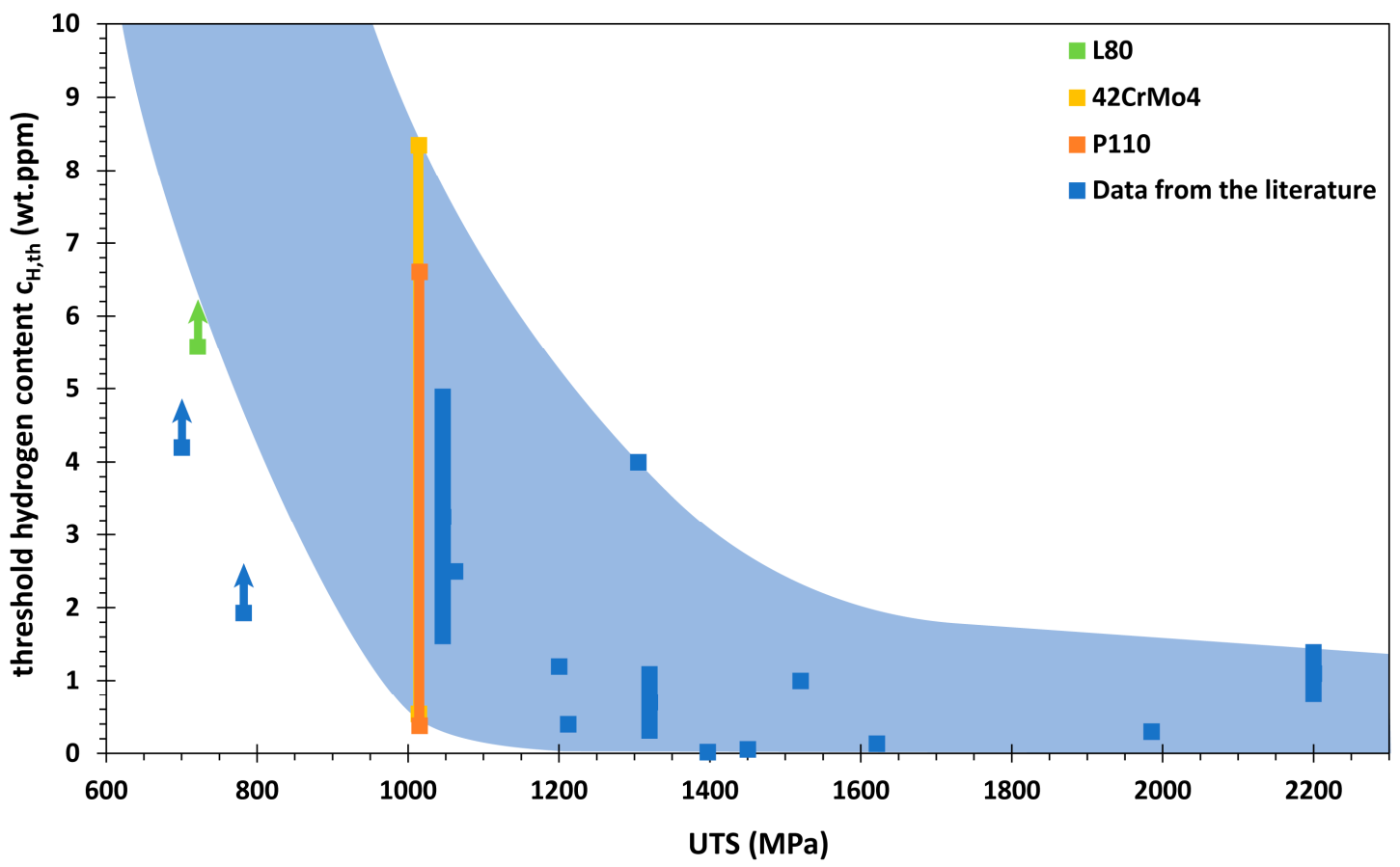

Figure 10. Threshold hydrogen content for hydrogen embrittlement of various martensitic and bainitic steel grades. Literature data from [19-24,42-44,52-54], missing values for UTS were estimated with YS $\times 1.10$.

\section{Conclusions}

The following conclusions can be drawn from the present work:

- $\mathrm{H}_{2}$ gas with a pressure of 20 and 100 bar results in an overall low hydrogen absorption. An increase of the partial pressure leads to a higher hydrogen content. Under dry gas conditions an increase in temperature results in a higher hydrogen absorption. The presence of electrolyte promotes hydrogen uptake from $\mathrm{H}_{2}$ gas at $25^{\circ} \mathrm{C}$.

- The hydrogen content achieved in autoclave tests with 100 bar $\mathrm{H}_{2}$ gas does not cause any substantial hydrogen embrittlement in specimens made from L80, 42CrMo4 and P110 under a constant load of $90 \%$ of the SMYS.

- The amount of hydrogen absorbed under conditions with $\mathrm{H}_{2} \mathrm{~S}$ is approximately one order of magnitude larger than for conditions with up to $100 \mathrm{bar}_{2}$ gas. The high hydrogen content leads to failures due to hydrogen embrittlement for $42 \mathrm{CrMo} 4$ and P110 at $90 \%$ of the SMYS. The sour service grade $\mathrm{L} 80$ does not crack during 14 days of immersion in $\mathrm{H}_{2} \mathrm{~S}$-saturated solution.

- Material strength and microstructure play a crucial role in the extent of hydrogen absorption and embrittlement.

- The threshold hydrogen content for hydrogen embrittlement under a constant load of $90 \%$ of the SMYS lies between $0.38 \mathrm{wt}$. ppm and $6.61 \mathrm{wt}$. ppm for the P110, between 0.54 and $8.35 \mathrm{wt}$. ppm for the $42 \mathrm{CrMo} 4$ and above $5.58 \mathrm{wt}$. ppm for the L80. This is in accordance with findings from the literature.

- The sour service steel grade L80 is suitable for application under the tested conditions with up to 100 bar $\mathrm{H}_{2}$ gas.

Author Contributions: A.T., G.M., M.O. and S.B. planned the experiments and interpreted the data, A.T. set up the experiments, conducted autoclave tests and prepared the graphs, A.T., C.H. and C.D. conducted ambient pressure tests, A.T. and G.M. prepared the draft paper, A.T., G.M., M.O. and S.B. did the corrections and revisions. G.M., M.O. and S.B. acquired funding. All authors have read and agreed to the published version of the manuscript. 
Funding: This research was partially funded by Austrian Federal Government's Climate and Energy Fund, which is represented by the Austrian Research Promotion Agency (FFG), project number 855231.

Acknowledgments: The authors would like to thank voestalpine BÖHLER Edelstahl GmbH \& Co KG for providing material for manufacturing of autoclaves.

Conflicts of Interest: The authors declare no conflict of interest. The funders had no role in the design of the study; in the collection, analyses, or interpretation of data; in the writing of the manuscript, or in the decision to publish the results.

\section{References}

1. Johnson, W.H. On some remarkable changes produced in iron and steel by the action of hydrogen and acids. Proc. R. Soc. Lond. 1875, 23, 168-179. [CrossRef]

2. Bhadeshia, H.K.D.H. Predictive Capabilities of Hydrogen Embrittlement Theories, and Prevention of the Embrittlement; Invited Talk in an Internal Workshop; HyResMat: Leibnitz, Austria, 2018.

3. Rawls, G.B.; Adams, T.; Newhouse, N.L. Hydrogen production and containment. In Gaseous Hydrogen Embrittlement of Materials in Energy Technologies: Volume 1: The Problem, Its Characterisation and Effects on Particular Alloy Classes; Somerday, B.P., Gangloff, R.P., Eds.; Woodhead Publishing Ltd.: Cambridge, UK, 2012; pp. 3-50. ISBN 9781845696771.

4. Sieverts, A.; Krumbhaar, W. Über die Löslichkeit von Gasen in Metallen und Legierungen. Ber. Dtsch. Chem. Ges. 1910, 43, 893-900. [CrossRef]

5. Iyer, R.N.; Takeuchi, I.; Zamanzadeh, M.; Pickering, H.W. Hydrogen Sulfide Effect on Hydrogen Entry into Iron-A Mechanistic Study. Corrosion 1990, 46, 460-468. [CrossRef]

6. Kawashima, A.; Hashimoto, K.; Shimodaira, S. Hydrogen Electrode Reaction and Hydrogen Embrittlement of Mild Steel in Hydrogen Sulfide Solutions. Corrosion 1976, 32, 321-331. [CrossRef]

7. Siegl, W.; Ecker, W.; Klarner, J.; Kloesch, G.; Mori, G.; Drexler, A.; Winter, G.; Schnideritsch, H. Hydrogen Trapping in Heat Treated and Deformed Armco Iron. In CORROSION 2019, Proceedings of the NACE Corrosion Conference and Expo 2019, Nashville, TN, USA, 24-28 March 2019; NACE International: Houston, TX, USA, 2019; p. 13083.

8. Fischer, F.D.; Mori, G.; Svoboda, J. Modelling the influence of trapping on hydrogen permeation in metals. Corros. Sci. 2013, 76, 382-389. [CrossRef]

9. Svoboda, J.; Mori, G.; Prethaler, A.; Fischer, F.D. Determination of trapping parameters and the chemical diffusion coefficient from hydrogen permeation experiments. Corros. Sci. 2014, 82, 93-100. [CrossRef]

10. Scharf, R.; Muhr, A.; Luckeneder, G.; Larour, P.; Mraczek, K.; Rehrl, J.; Leomann, F.; Stellnberger, K.-H.; Faderl, J.; Mori, G. Hydrogen embrittlement of DP-1000 flat steel sheet: Influence of mechanical properties, specimen geometry, pre-damaging and electrolytically zinc galvanizing. Mater. Corros. 2016, 67, 239-250. [CrossRef]

11. NACE International. Petroleum, Petrochemical, and Natural Gas Industries-Materials for Use in $\mathrm{H}_{2}$ s-Containing Environments in Oil and Gas Production; ANSI/NACE MR0175/ISO 15156:2015; NACE International: Houston, TX, USA, 2015.

12. Asahi, H.; Ueno, M. Effect of Austenite Grain Size on Sulfide Stress Cracking Resistance of Low Alloy Martensitic Steels. ISIJ Int. 1992, 32, 1021-1026. [CrossRef]

13. Asahi, H.; Sogo, Y.; Ueno, M.; Higashiyama, H. Metallurgical Factors Controlling SSC Resistance of High-Strength, Low-Alloy Steels. Corrosion 1989, 45, 519-527. [CrossRef]

14. Thompson, A.W.; Bernstein, I.M. The Role of Metallurgical Variables in Hydrogen-Assisted Environmental Fracture. In Advances in Corrosion Science and Technology; Fontana, M.G., Staehle, R.W., Eds.; Springer: Boston, MA, USA, 1980; pp. 53-175. ISBN 978-1-4615-9065-1.

15. Snape, E. Roles of Composition and Microstructure in Sulfide Cracking of Steel. Corrosion 1968, 24, $261-282$. [CrossRef]

16. American Petroleum Institute. Specification for Casing and Tubing, 9th ed.; American Petroleum Institute: Washington, DC, USA, 2011.

17. Solheim, K.G.; Solberg, J.K.; Walmsley, J.; Rosenqvist, F.; Bjørnå, T.H. The role of retained austenite in hydrogen embrittlement of supermartensitic stainless steel. Eng. Fail. Anal. 2013, 34, 140-149. [CrossRef] 
18. Bacchi, L.; Biagini, F.; Corsinovi, S.; Romanelli, M.; Villa, M.; Valentini, R. Influence of Thermal Treatment on SCC and HE Susceptibility of Supermartensitic Stainless Steel 16Cr5NiMo. Materials 2020, 13, 1643. [CrossRef] [PubMed]

19. Lovicu, G.; Bottazzi, M.; D'Aiuto, F.; de Sanctis, M.; Dimatteo, A.; Santus, C.; Valentini, R. Hydrogen Embrittlement of Automotive Advanced High-Strength Steels. Metall. Mater. Trans. A 2012, 43, 4075-4087. [CrossRef]

20. Asahi, H.; Ueno, M.; Yonezawa, T. Prediction of Sulfide Stress Cracking in High-Strength Tubulars. Corrosion 1994, 50, 537-545. [CrossRef]

21. Peral, L.B.; Zafra, A.; Rodríguez, C.; Belzunce, J. Evaluation of strength and fracture toughness of ferritic high strength steels under hydrogen environments. Procedia Struct. Integr. 2017, 5, 1275-1282. [CrossRef]

22. Hüter, C.; Shanthraj, P.; McEniry, E.; Spatschek, R.; Hickel, T.; Tehranchi, A.; Guo, X.; Roters, F. Multiscale Modelling of Hydrogen Transport and Segregation in Polycrystalline Steels. Metals 2018, 8, 430. [CrossRef]

23. Wang, M.; Akiyama, E.; Tsuzaki, K. Determination of the critical hydrogen concentration for delayed fracture of high strength steel by constant load test and numerical calculation. Corros. Sci. 2006, 48, 2189-2202. [CrossRef]

24. Wang, M.; Akiyama, E.; Tsuzaki, K. Effect of hydrogen and stress concentration on the notch tensile strength of AISI 4135 steel. Mater. Sci. Eng. A 2005, 398, 37-46. [CrossRef]

25. Todoshchenko, O.; Yagodzinskyy, Y.; Hänninen, H. Hydrogen Uptake and Embrittlement Susceptibility of Ferrite-Pearlite Pipeline Steels. In Materials Performance in Hydrogen Environments, Proceedings of the 2016 International Hydrogen Conference, Jackson Lake Lodge, Wyoming, USA, 11-14 September 2016; Somerday, B.P., Sofronis, P., Eds.; ASME Press: New York, NY, USA, 2017; pp. 487-494. ISBN 9780791861387.

26. Revie, R.W.; Sastri, V.S.; Hoey, G.R.; Ramsingh, R.R.; Mak, D.K.; Shehata, M.T. Hydrogen-Induced Cracking of Linepipe Steels Part 1-Threshold Hydrogen Concentration and pH. Corrosion 1993, 49, 17-23. [CrossRef]

27. Kittel, J.; Martin, J.W.; Cassagne, T.; Bosch, C. Hydrogen Induced Cracking (HIC)—Laboratory Testing Assessment Of Low Alloy Steel Linepipe. In CORROSION 2008, Proceedings of the NACE Corrosion Conference and Expo 2008, New Orleans, LA, USA, 16-20 March 2008; NACE International: Houston, TX, USA, 2008; p. 08100.

28. van Gelder, K.; Simon Thomas, M.J.J.; Kroese, C.J. Hydrogen-Induced Cracking: Determination of Maximum Allowed $\mathrm{H}_{2} \mathrm{~S}$ Partial Pressures. Corrosion 1986, 42, 36-43. [CrossRef]

29. Kappes, M.; Frankel, G.S.; Thodla, R.; Mueller, M.; Sridhar, N.; Carranza, R.M. Hydrogen Permeation and Corrosion Fatigue Crack Growth Rates of X65 Pipeline Steel Exposed to Acid Brines Containing Thiosulfate or Hydrogen Sulfide. Corrosion 2012, 68, 1015-1028. [CrossRef]

30. Hara, T.; Asahi, H.; Terada, Y.; Shigenobu, T.; Ogawa, H. The Condition of HIC Occurrence of X65 Linepipe in Wet $\mathrm{H}_{2} \mathrm{~S}$ Environments. In CORROSION 99, Proceedings of the NACE Corrosion 99, San Antonio, TX, USA, 25-30 April 1999; NACE International: Houston, TX, USA, 1999; p. 99429.

31. Wang, R. Effects of hydrogen on the fracture toughness of a X70 pipeline steel. Corros. Sci. 2009, 51, $2803-2810$. [CrossRef]

32. Nguyen, T.T.; Park, J.S.; Kim, W.S.; Nahm, S.H.; Beak, U.B. Environment hydrogen embrittlement of pipeline steel X70 under various gas mixture conditions with in situ small punch tests. Mater. Sci. Eng. A 2020, 781, 139114. [CrossRef]

33. Zhang, T.; Chu, W.Y.; Gao, K.W.; Qiao, L.J. Study of correlation between hydrogen-induced stress and hydrogen embrittlement. Mater. Sci. Eng. A 2003, 347, 291-299. [CrossRef]

34. Meng, B.; Gu, C.; Zhang, L.; Zhou, C.; Li, X.; Zhao, Y.; Zheng, J.; Chen, X.; Han, Y. Hydrogen effects on X80 pipeline steel in high-pressure natural gas/hydrogen mixtures. Int. J. Hydrogen Energy 2017, 42, 7404-7412. [CrossRef]

35. Briottet, L.; Batisse, R.; de Dinechin, G.; Langlois, P.; Thiers, L. Recommendations on X80 steel for the design of hydrogen gas transmission pipelines. Int. J. Hydrogen Energy 2012, 37, 9423-9430. [CrossRef]

36. Moro, I.; Briottet, L.; Lemoine, P.; Andrieu, E.; Blanc, C.; Odemer, G. Hydrogen embrittlement susceptibility of a high strength steel X80. Mater. Sci. Eng. A 2010, 527, 7252-7260. [CrossRef] 
37. Nagao, A.; Takagi, S.; Ishikawa, N.; Kimura, M. Hydrogen Uptake in Steels Exposed to High-Pressure $\mathrm{H}_{2}$ Gas. In Materials Performance in Hydrogen Environments, Proceedings of the 2016 International Hydrogen Conference, Jackson Lake Lodge, Wyoming, USA, 11-14 September 2016; Somerday, B.P., Sofronis, P., Eds.; ASME Press: New York, NY, USA, 2017; pp. 462-469. ISBN 9780791861387.

38. Wada, Y.; Tanaka, Y.; Iwadate, T.; Ohmi, T.; Yokobori, T. Effect of Specimen Size on Hydrogen Embrittlement Cracking of 2.25Cr-1Mo Heavy Section Steel for Pressure Vessels. J. Jpn. Inst. Met. 2007, 71, 772-780. [CrossRef]

39. Al-Rumaih, A.M.; Gangloff, R.P. Measurement and Modeling of Temperature Dependent Internal Hydrogen Assisted Cracking in Cr-Mo Steel. In Hydrogen-Materials Interactions, Proceedings of the 2012 International Hydrogen Conference, Grand Teton National Park, Wyoming, USA, 9-12 September 2012; Somerday, B.P., Sofronis, P., Eds.; American Society Of Mechanical Engineers: New York, NY, USA, 2014; pp. $33-48$. ISBN 9780791860298.

40. Hosseini, Z.S.; Dadfarnia, M.; Nibur, K.A.; Somerday, B.P.; Gangloff, R.P. Trapping Against Hydrogen Embrittlement. In Materials Performance in Hydrogen Environments, Proceedings of the 2016 International Hydrogen Conference, Jackson Lake Lodge, Wyoming, USA, 11-14 September 2016; Somerday, B.P., Sofronis, P., Eds.; ASME Press: New York, NY, USA, 2017; pp. 71-80. ISBN 9780791861387.

41. Pillot, S.; Nibur, K.A.; Gangloff, R.P. Hydrogen Cracking of Cr-Mo-V Steel from High Pressure $\mathrm{H}_{2}$ Service. In SteelyHydrogen2014 Conference, Proceedings of the 2nd International Conference on Metals and Hydrogen, Ghent, Belgium, 5-7 May 2014; Duprez, L., Zermout, Z., Eds.; OCAS: Ghent, Belgium, 2014; pp. $433-447$. ISBN 9789081794213.

42. Álvarez, G.; Zafra, A.; Belzunce, F.J.; Rodríguez, C. Hydrogen embrittlement analysis in a CrMoV steel by means of sent specimens. Theor. Appl. Fract. Mech. 2020, 106, 102450. [CrossRef]

43. Venezuela, J.; Tapia-Bastidas, C.; Zhou, Q.; Depover, T.; Verbeken, K.; Gray, E.; Liu, Q.; Liu, Q.; Zhang, M.; Atrens, A. Determination of the equivalent hydrogen fugacity during electrochemical charging of $3.5 \mathrm{NiCrMoV}$ steel. Corros. Sci. 2018, 132, 90-106. [CrossRef]

44. Atrens, A.; Liu, Q.; Tapia-Bastidas, C.; Gray, E.; Irwanto, B.; Venezuela, J.; Liu, Q. Influence of Hydrogen on Steel Components for Clean Energy. Corros. Mater. Degrad. 2018, 1, 3-26. [CrossRef]

45. Shim, I.-O.; Byrne, J.G. A study of hydrogen embrittlement in 4340 steel I: Mechanical aspects. Mater. Sci. Eng. A 1990, 123, 169-180. [CrossRef]

46. Farrell, K. Cathodic Hydrogen Absorption and Severe Embrittlement in a High Strength Steel. Corrosion 1970, 26, 105-110. [CrossRef]

47. Bandyopadhyay, N.; Kameda, J.; McMahon, C.J. Hydrogen-induced cracking in 4340-type steel: Effects of composition, yield strength, and $\mathrm{H}_{2}$ pressure. MTA 1983, 14, 881-888. [CrossRef]

48. Das, T.; Legrand, E.; Brahimi, S.V.; Song, J.; Yue, S. Evaluation of material susceptibility to hydrogen embrittlement (HE): An approach based on experimental and finite element (FE) analyses. Eng. Fract. Mech. 2020, 224, 106714. [CrossRef]

49. Garrison, W.M.; Moody, N.R. Hydrogen embrittlement of high strength steels. In Gaseous Hydrogen Embrittlement of Materials in Energy Technologies: Volume 2: Mechanisms, Modelling and Future Developments Theory and Practice; Somerday, B.P., Gangloff, R.P., Eds.; Woodhead Publishing: Cambridge, UK; Philadelphia, PA, USA, 2012; pp. 421-492. ISBN 978-0-85709-537-4.

50. Scharf, R.; Muhr, A.; Stellnberger, K.-H.; Faderl, J.; Holzer, C.; Mori, G. Hydrogen embrittlement of high strength steel under in situ corrosive charging conditions and tensile load. Mater. Corros. 2017, 68, 95-104. [CrossRef]

51. Zhu, X.; Li, W.; Zhao, H.; Wang, L.; Jin, X. Hydrogen trapping sites and hydrogen-induced cracking in high strength quenching \& partitioning (Q\&P) treated steel. Int. J. Hydrogen Energy 2014, 39, 13031-13040. [CrossRef]

52. Kim, J.S.; Lee, Y.H.; Lee, D.L.; Park, K.-T.; Lee, C.S. Microstructural influences on hydrogen delayed fracture of high strength steels. Mater. Sci. Eng. A 2009, 505, 105-110. [CrossRef]

53. Thomas, R.L.S.; Scully, J.R.; Gangloff, R.P. Internal hydrogen embrittlement of ultrahigh-strength AERMET 100 steel. Met. Mat. Trans. A 2003, 34, 327-344. [CrossRef] 
54. Mori, G.K.; Feyerl, J.; Zitter, H. The Influence of Hydrogen Content and Stress Level on Hydrogen Embrittlement of Bainitic Carbon Steel Fasteners. In CORROSION 2002, Proceedings of the NACE Corrosion Conference and Expo 2002, Denver, CO, USA, 7-11 April 2002; NACE International: Houston, TX, USA, 2002; p. 02430.

55. Trautmann, A.; Mori, G.; Siegl, W.; Truschner, M.; Pfeiffer, J.; Kapp, M.; Keplinger, A.; Oberndorfer, M.; Bauer, S. Hydrogen uptake of duplex 2205 at $\mathrm{H}_{2}$ partial pressures up to 100 bar. In ESSC and DUPLEX 2019, Proceedings of the10th European Stainless Steel Conference-Science and Market, 6th European Duplex Stainless Steel Conference and Exhibition, Vienna, Austria, 30 September-2 October 2019; ASMET: Leoben, Austria, 2019; pp. 338-345.

56. Takai, K.; Murakami, K.; Yabe, N.; Suzuki, H.; Hagihara, Y. Properties of Thermal Hydrogen Desorption and Substitution of High-Pressure Gas Charging by Electrolysis Charging for Inconel 625 and SUS 316L. J. Jpn. Inst. Met. 2008, 72, 448-456. [CrossRef]

57. Whiteman, M.B.; Troiano, A.R. Hydrogen Embrittlement of Austenitic Stainless Steel. Corrosion 1965, 21, 53-56. [CrossRef]

58. ASTM International. Practice for X-Ray Determination of Retained Austenite in Steel with Near Random Crystallographic Orientation; ASTM International: West Conshohocken, PA, USA, 2013.

59. Trautmann, A.; Oberndorfer, M.; Mori, G.; Bauer, S. Susceptibility of Selected Steel Grades to Hydrogen Embrittlement-Simulating Field Conditions by Performing Laboratory Wheel Tests with Autoclaves. In CORROSION 2019, Proceedings of the NACE Corrosion Conference and Expo 2019, Nashville, TN, USA, 24-28 March 2019; NACE International: Houston, TX, USA, 2019; p. 13402.

60. Trautmann, A.; Mori, G.; Siegl, W.; Truschner, M.; Pfeiffer, J.; Kapp, M.; Keplinger, A.; Oberndorfer, M.; Bauer, S. Hydrogen Uptake of Duplex 2205 at $\mathrm{H}_{2}$ Partial Pressures up to 100 bar. Berg Huettenmaenn Mon. 2020, 165, 40-45. [CrossRef]

61. NACE International. Laboratory Testing of Metals for Resistance to Sulfide Stress Cracking and Stress Corrosion Cracking in $\mathrm{H}_{2} \mathrm{~S}$ Environments; TM0177-2016; NACE International: Houston, TX, USA, 2016.

62. Martin, R.L. Corrosion Inhibitors for Oil and Gas Production. In ASM Handbook Volume 13A: Corrosion: Fundamentals, Testing, and Protection, 10th ed.; Cramer, S.D., Covino, B.S., Jr., Eds.; ASM International: Materials Park, OH, USA, 2003; pp. 878-886. ISBN 978-0-87170-705-5. 